\title{
Open surgery for haemorrhoids in persons with spinal cord injury
}

\author{
JG Previnaire ${ }^{1} \cdot \mathrm{N}$ De Bont ${ }^{1} \cdot \mathrm{H} \mathrm{Bordi}^{1} \cdot \mathrm{N} \mathrm{Senal}^{1} \cdot$ PE Mortier $^{2,3}$
}

Received: 23 February 2018 / Revised: 21 March 2018 / Accepted: 21 March 2018

(C) International Spinal Cord Society 2018

\begin{abstract}
Study design Pilot retrospective study on the outcome of open surgery for grade III and IV haemorrhoids in patients with SCI.

Objective Haemorrhoids and anal fissures are common in patients with spinal cord injury (SCI). Grade I to III haemorrhoids are usually managed medically or by surgical ligation. Grade III and IV haemorrhoids are treated with surgical haemorrhoidectomy in the general population, but not in patients with SCI, most probably due to fear of complications.

Setting Fondation Hopale, Berck-sur Mer, France

Methods The surgical database was searched for open haemorrhoidectomies performed between 2007 and 2016. Seventeen patients were included. There were mostly males with complete paraplegia, mean age: 50 years and mean time since injury: 15.9 years. Open haemorrhoidectomy (Milligan and Morgan) was performed for isolated haemorrhoids $(n=4)$, and combined with Leopold Bellan procedure (posterior anoplasty and internal sphincterotomy) for associated anal fissures $(n=13)$. Short-term follow-up was performed by the surgeon (post-operative weeks 2 and 6), long-term follow-up by telephone interview (mean 5.7 years, SD 1.9).

Results At 6-weeks post-operative, no significant complications had occurred and all wounds had healed, however 1 patient had recurrence of anal fissure. At long-term follow-up, 75\% of patients reported a significant improvement in anorectal symptoms. Recurrences were reported by 5 patients: 3 haemorrhoids (18\%) and 2 anal fissures (25\%). Anal incontinence occurred in 1 patient who required an anal plug. All patients maintained the same bowel programs as pre-operative.

Conclusions Open surgery procedures were well tolerated and should be considered in persons with SCI.
\end{abstract}

\section{Introduction}

Gastrointestinal problems are common in patients with neurological diseases. Symptoms include bloating, difficulty evacuating stools, faecal incontinence, dyschesia, bleeding, anal fissures, and haemorrhoids [1-4]. A recent study found moderate to severe bowel symptoms in $61 \%$ of patients with spinal cord injury (SCI), $43 \%$ in patients with multiple sclerosis and $23 \%$ in patients with hemiplegia [4]. Haemorrhoids occur more frequently in patients with SCI

JG Previnaire

previnjg@hopale.com

1 Spinal Department, Centre Calvé, Fondation Hopale, Berck-surMer, France

2 Department of Gastroenterology, Institut Calot, Fondation Hopale, Berck-sur-Mer, France

3 Department of Gastroenterology, Centre Hospitalo-Universitaire de Lille, Lille, France than in patients with any other neurological disorder, with an estimated prevalence of up to $74 \%[4,5]$. Symptoms associated with haemorrhoids include acute or chronic rectal bleeding, difficulty evacuating and anal discomfort. These symptoms affect the patient's quality of life [2-4]. The mechanism behind the development of haemorrhoids remains unclear. Risk factors include straining during stool evacuation and chronic trauma from digital stimulation for stool removal or reflex evacuation [6].

Treatment for haemorrhoids is the same in patients with SCI as in the general population [7]. Medical management is the treatment of choice for grade I internal (non prolapsing) haemorrhoids. This includes a wide variety of interventions, which are largely empirical (high-fibre diet, adequate fluid intake, stool softeners, topical and systemic analgesics etc.). Rubber band ligation is the most common treatment for grade II (protrude but reduce spontaneously) and grade III (protrude and require manual reduction) haemorrhoids. Grade III haemorrhoids with severe symptoms and grade IV (remain prolapsed) haemorrhoids are best treated by surgical haemorrhoidectomy [7]. 
Table 1 Patient characteristics

\begin{tabular}{lllllll}
\hline Gender ratio & Level & AIS & Motor neuron lesion & Age & Time since injury & Follow-up \\
\hline 15 males & 3 tetraplegia & A: 15 & UMN: 15 & 50.1 years & 15.9 years & 5.8 years \\
2 females & 14 paraplegia & B: 2 & LMN: 2 & $(39.5-59.4)$ & $(0.4-36.9)$ & $(0.8-8.9)$ \\
\hline
\end{tabular}

AIS Asia impairment scale

$U M N$ upper motor neuron

LMN lower motor neuron

The evidence for non-surgical treatments is surprisingly limited $[6,8,9]$ and few descriptions of surgical haemorrhoidectomy [8] in patients with SCI can be found in the literature. Both medical treatments and ligation are quite safe but are associated with a high rate of recurrence $[6,8$, 9]. In their most recent retrospective study on ligations in patients with SCI, Cosman et al. reported that 86 out of 215 patients required repeated banding procedures (range, 2-11 procedures), with a mean interval between procedures of $2.9 \pm 3.5$ years [8]. While haemorrhoidectomy could offer a long-term solution, it is widely believed by physicians, surgeons and the patients themselves, to be associated with post-operative complications in the case of SCI [6].

The aim of this study was to evaluate the short-term and long-term outcome of surgical treatment for haemorrhoids in patients with SCI.

\section{Materials and methods}

The surgical database was searched for open haemorrhoidectomies performed between 2007 and 2016 at the Calot clinic. Inclusion criteria were persons with SCI and grade III or IV haemorrhoids. There were no exclusion criteria.

All procedures were performed by the same gastroenterologist (MPE). Open haemorrhoidectomy (Milligan and Morgan procedure) was performed for isolated haemorrhoids. It is a four-step procedure[10]:

- placement of three sets of clamps on each haemorrhoidal pedicle: on the peri-anal skin, at the dentate line and on the rectal mucosa;

- dissection and individual ligation of each of the three pedicles with absorbable sutures;

- trimming of the muco-cutaneous bridges between each dissected pedicle, in order to remove the underlying residual haemorrhoidal tissues;

- division of the pedicle, leaving a mucosal stump of approximately $5 \mathrm{~mm}$.

This was combined with a Leopold Bellan procedure that involves a fourth posterior incision and posterior anoplasty for associated anal fissures [10].
Surgery was performed under general anaesthesia and bilateral pudendal nerve block. The wounds were left open at the end of the procedure to heal by secondary intention. Haemorrhoidectomies were performed either as an outpatient or an inpatient procedure with a maximum of 3 days stay for patients with comorbidities. Patients were allowed to sit in their wheelchair from the first day post-surgery. Prophylactic antibiotics (mainly metronidazole) were administered for 5 days, starting on the day of surgery.

All patients underwent clinical follow-up evaluation by the surgeon at weeks 2 and 6 after surgery (short-term follow-up).

For the long-term follow-up, previously scheduled telephone interviews were performed by a physical and rehabilitation medicine intern. The interview was divided into three sections: bowel care and habits, haemorrhoid symptoms and treatment outcome.

Primary outcome measures were short term complications and rate of recurrence. Secondary outcome measures were improvement of anorectal symptoms and quality of life rated with the Patient Global Impression of Improvement (PGI-I), and anal discomfort rated with the Patient Global Impression of Severity (PGI-S) [4, 11].

\section{Results}

Data for 25 patients were eligible for inclusion, however since the intervention, 4 patients had died (of causes unrelated to the procedure) and 4 others could not be contacted (they had moved and changed phone number). The 17 remaining patients were contacted and gave their consent to take part in the study. Their characteristics are shown in Table 1. All patients had sustained a traumatic SCI: there were 3 patients with tetraplegia, 7 with high-level (T1-T6) paraplegia and 7 with low-level (below T6) paraplegia, including 2 with cauda equina and lower motor neuron lesions. Fifteen patients had complete motor and sensory lesions (AIS A) and 2 had complete motor but incomplete sensory lesions (AIS B) [12]. Two of the patients included underwent open haemorrhoidectomy following failure of ligation. During the same period, a total of 44 haemorrhoid ligations (rubber band) were performed in 38 patients. A total of 63 patients thus required either haemorrhoid surgery 
or ligation out of approximately three thousand patients with SCI followed in our centre over the last 40 years.

The Milligan and Morgan procedure was performed alone in 4 cases and associated with a Leopold Bellan procedure [13] in 13 cases (simple haemorrhoidectomy ( $n$ $=1$ ) or associated with anal fissures $(n=12)$ ). The patients' main complaints before surgery were rectal bleeding and difficulty evacuating. Pre-intervention bowel programs were: digital stool removal $(n=13)$, straining $(n=2)$, transanal irrigation $(n=1)$ and enema $(n=1)$. Thirteen patients used intermittent catheterisation and 4 carried out reflex voiding.

\section{Short-term outcomes}

Short-term complications were only minor, with bleeding the most common (4 patients). This resolved in all cases with no need for sutures or transfusion. No local infections that required additional courses of antibiotics occurred. The patient with sensation (AIS B) experienced pain that was successfully treated with non-steroidal anti-inflammatory drugs (ketoprofen). Episodes of mild, transient autonomic dysreflexia with headaches as the main symptom occurred in 4 patients.

All wounds healed between week $2(n=8)$ and week 6 $(n=9)$. Recurrence of anal fissure occurred in 1 patient (with cauda equina lesion) before week 6 .

\section{Long-term outcomes}

Mean follow-up was 5.7 years (SD: 1.9) (Table 2 and 3). Eighty-two percent of patients $(n=14)$ reported complete $(n=9)$ or partial $(n=5)$ cessation of bleeding. Five patients reported recurrences between the 6th week and long-term follow-ups: 3 haemorrhoids $(18 \%-1$ patient with tetraplegia and 2 with high-level paraplegia - all had undergone Leopold Bellan procedures) and 2 anal fissures (1 patient with tetraplegia and one with low-level paraplegia, total recurrence: 25\%) (Table 2). One patient with high-level paraplegia required further surgery to reduce the haemorrhoids. The 2 patients with a previous history of haemorrhoid ligations had complete improvement.

Table 2 Outcome of open surgery

\begin{tabular}{lll}
\hline & Haemorrhoids & Anal fissures \\
\hline Cured / improved & 9 cured & 9 cured \\
& 5 improved & \\
Recurrence & 3 recurrences $(18 \%)$ & $\begin{array}{l}3 \text { recurrences } \\
(1 \text { before } 6 \text { weeks } \\
2 \text { after } 6 \text { weeks }) \\
\end{array}$ \\
& & $(25 \%)$ \\
Total & 17 & 12 \\
\hline
\end{tabular}

Recurrence of haemorrhoids and fissures occurred in patients who carried out digital stool removal. No anal stenosis was found on anal examination at the short-term or long-term follow-ups. Incontinence (gas and faeces) occurred in 1 patient after a Leopold Bellan procedure (for combined haemorrhoids and anal fissure), which was successfully treated with an anal plug (Peristeen ${ }^{\circledR}$ ). Bowel programs remained unchanged in all patients after surgery.

PGI-S was rated in 15 of the 17 patients at the long-term follow-up. Mild $(n=5)$ or no $(n=5)$ anorectal discomfort was rated by $67 \%$ of patients and moderate or severe discomfort in $33 \%(n=5)$. The PGI-I was rated by 16 of the 17 patients. Twelve patients reported a significant improvement in anorectal symptoms (very much or much improved, 75\%), 1 patient a significant worsening (that required further surgery), while 3 reported no change or slight improvement in symptoms (19\%). Quality of life was considered unchanged for 12 patients (same, a little improved or a little worse, $75 \%$ ), improved for 3 (very much or much, 19\%) and much worse for 1 (6\%) (Table 3). Eighty-eight percent of patients $(n=14)$ stated they would undergo the same procedure again if necessary.

\section{Discussion}

To our knowledge, this is the first pilot retrospective study to report results of haemorrhoidectomy with or without associated fissurectomy in patients with SCI. In the general population, approximately one in ten patients with haemorrhoids require surgical treatment, i.e., removal of haemorrhoidal tissues [10, 14]. Different techniques exist, however most are associated with the same complications [10]. A recent study evaluated the 1-year outcome of open haemorrhoidectomy in 633 patients, 36\% involving the Milligan and Morgan procedure and $64 \%$ the Leopold Bellan procedure [15]. Immediate complications were reported in $6.9 \%$ of patients, including urinary retention, faecal impaction, secondary haemorrhage requiring haemostasis and local infection. Urinary retention and faecal impaction were unlikely to occur in the present study since most patients carried out intermittent catheterisation and digital stool removal. Bleeding was the most common complication (4 patients (24\%)); however, it resolved without need for additional treatment. Post-operative pain only occurred in 1 patient with an incomplete sensory (AIS B) lesion. Other early complications reported in the literature are anal stenosis and local infections [10], neither of which occurred in the present study.

Wound healing and autonomic dysreflexia are important issues to consider when carrying out anorectal procedures in patients with complete SCI. Patients with SCI have a higher risk of pressure sores, especially in the sacral, ischial and 
Table 3 Long-term satisfaction and quality of life

\begin{tabular}{lllllll}
\hline & $\begin{array}{l}\text { Very much } \\
\text { improved }\end{array}$ & $\begin{array}{l}\text { Much } \\
\text { improved }\end{array}$ & $\begin{array}{l}\text { A little } \\
\text { improved }\end{array}$ & Same & $\begin{array}{l}\text { A little } \\
\text { worse }\end{array}$ & $\begin{array}{l}\text { Much } \\
\text { worse }\end{array}$ \\
\hline Satisfaction & 6 & 6 & 1 & 2 & - & $\begin{array}{l}\text { Very much } \\
\text { worse }\end{array}$ \\
Quality of life & 1 & 2 & 1 & 10 & 1 & 1 \\
\hline
\end{tabular}

PGI-I patient global impression of improvement $(n=16)$

pelvic areas. Creating an open wound around the anus thus has high risks. Despite this, all wounds healed within six weeks, which is actually faster than in the general population (90\% at 10 weeks) [10]. This could be attributed to the lack of pain that allowed patients to get out of bed and sit from the first post-operative day.

Autonomic dysreflexia is defined as an increase in systolic blood pressure ( $\geq 20 \mathrm{mmHg}$ above baseline) in response to stimuli below the level of injury. This occurs typically in patients with SCI at and above T6, and may include several signs and symptoms (headache, flushing and sweating, dysrhythmia) $[16,17]$. In particular, bladder distension or contractions, and any anal procedures for stool removal (such as the introduction of a suppository or a finger) are potent stimuli for autonomic dysreflexia. In order to control autonomic dysreflexia, all procedures were carried out under general anaesthesia with a bilateral pudendal nerve block [18]. After surgery, only mild episodes of autonomic dysreflexia occurred in 4 patients, which is similar to the frequency reported following haemorrhoid ligations $[6,8]$. The fact that $88 \%$ of the patients said they would undergo the same operation again if necessary highlights the fact that haemorrhoidectomy was well tolerated, but we strongly propose that it should be performed in a centre with staff experienced in SCI.

In the general population, the reported incidence of anal incontinence after haemorrhoidectomy varies from 2 to $12 \%$, depending on the definition adopted by the authors $[10,15]$. Incontinence is caused by the excision of the anal cushions (connective tissue complexes that contain smooth cells and vascular channels), which generate up to $15 \%$ of the resting pressure [19], post-operative scar tissue formation that reduces sensation in the transitional zone and lateral internal sphincterotomy [13]. In this study, only 1 patient $(6 \%)$ experienced incontinence (mixed gas and faecal).

In contrast with haemorrhoid ligation that is carried out to reduce symptoms, haemorrhoidectomy is a long-term treatment. The results showed a recurrence rate of $18 \%$ (3 patients). This is higher than in the general population in which recurrence at one year is around $5 \%$, but can be as low as $1 \%$ [10]. Interpretation of the results must take into account the longer follow-up in the present study (5.8 years vs. 1 year) and the fact that the majority of patients underwent more complex procedures to correct anal fissures (12 of the 17 patients). Furthermore, the risk factors for haemorrhoids persisted since the patients' bowel programs did not change after surgery. The rate of satisfaction, although good, was lower than in studies in the general population (75 vs. 90\%) [15, 20].

Anal fissure is another complication related to gastrointestinal problems in persons with SCI. Risk factors include the passage of hard and bulky stools resulting in tears of the anoderm, hypertonia or spasm of the internal sphincter in reaction to raw ulceration, local ischaemia of the anoderm and repeated trauma caused by digital stimulation [21]. In France, there is no consensus regarding medical treatment for anal fissures. Non-specific treatment is always offered first-line and nitroglycerin rectal ointments as second-line, with healing rates between 8 and $31 \%$, and 33 and 49\%, respectively [21]. The 25\% (3 patients) recurrence rate of fissures in this study is higher than in the general population $(11.6 \%$ with mean follow-up of 8.2 years) [22]. This is likely due to the complexity of the surgical procedures carried out and the use of digital stool removal by most patients.

Strikingly, all 17 patients who took part in this study had the most severe SCI (AIS A or B), i.e., complete motor lesions. Previous studies in persons with SCI have shown a significant relationship between severity of SCI and severity of neurogenic bowel dysfunction, using the NBD score or the PGI-S [3, 4, 23]. It would appear that patients with complete motor lesions are particularly at risk of developing haemorrhoids. By contrast, previous studies did not find any influence of the level of lesion on the frequency of slow transit or difficulty defaecating [24], constipation or incontinence[3] or NBD score [4].

\section{Limitations}

The small sample size limits the ability to make strong conclusions and to statistically compare subgroups. The severity of neurogenic bowel dysfunction was not assessed prior to surgery, preventing further analysis of risk factors for haemorrhoids.

\section{Conclusion}

This pilot retrospective study of open surgery for grade III and IV haemorrhoids in patients with SCI found high levels 
of satisfaction and low rates of complications that were similar to rates in the general population. In particular, all wounds healed within 6 weeks and autonomic dysreflexia was controlled in all patients.

These open surgery procedures were well tolerated and should thus be proposed to persons with SCI in the case of severe anorectal disorders. Further prospective studies should try to determine the impact of level, severity and type (motor neuron) of lesions on the recurrence of haemorrhoids and anal fissures. The risk of anal incontinence should be more specifically evaluated using anorectal manometry.

Acknowledgements We are grateful to Johanna Robertson for revision of the English.

\section{Compliance with ethical standards}

Conflict of interest The authors declare that they have no conflict of interest.

\section{References}

1. Coggrave M, Norton C, Cody JD. Management of faecal incontinence and constipation in adults with central neurological diseases. Cochrane Database Syst Rev. 2014. Art. No. CD002115. https://doi.org/10.1002/14651858.CD002115.pub5.

2. Emmanuel A. Review of the efficacy and safety of transanal irrigation for neurogenic bowel dysfunction. Spinal Cord. 2010;48:664-73.

3. Krogh K, Nielsen J, Djurhuus JC, Mosdal C, Sabroe S, Laurberg $\mathrm{S}$. Colorectal function in patients with spinal cord lesions. Dis Colon Rectum. 1997;40:1233-9.

4. Previnaire JG, Soler JM, Bordji H, Fiolet MC, Navaux MA, Mortier PE. [Assessment of severity of neurogenic bowel dysfunction in chronic patients with a simple 1-item questionnaire (PGI-S)]. Prog Urol. 2016;26:573-81.

5. Stone JM, Nino-Murcia M, Wolfe VA, Perkash I. Chronic gastrointestinal problems in spinal cord injury patients: a prospective analysis. Am J Gastroenterol. 1990;85:1114-9.

6. Cosman BC, Eastman DA, Perkash I, Stone JM. Hemorrhoidal bleeding in chronic spinal cord injury: results of multiple banding. Int J Colorectal Dis. 1994;9:174-6.

7. Wald A, Bharucha AE, Cosman BC, Whitehead WE. ACG clinical guideline: management of benign anorectal disorders. Am J Gastroenterol. 2014;109:1141-57.

8. Cosman BC, Cajas-Monson LC, Ramamoorthy SL. Twenty years of a veterans' spinal cord injury colorectal clinic: flexible sigmoidoscopy and multiple hemorrhoid ligation. Dis Colon Rectum. 2017;60:399-404.
9. Scott D, Papa MZ, Sareli M, Velano A, Ben-Ari GY, Koller M. Management of hemorrhoidal disease in patients with chronic spinal cord injury. Tech Coloproctol. 2002;6:19-22.

10. Moult HP, Aubert M, De Parades V. Classical treatment of hemorrhoids. J Visc Surg. 2015;152:S3-9.

11. Viktrup L, Hayes RP, Wang P, Shen W. Construct validation of patient global impression of severity (PGI-S) and improvement (PGI-I) questionnaires in the treatment of men with lower urinary tract symptoms secondary to benign prostatic hyperplasia. BMC Urol. 2012;12:30.

12. Kirshblum SC, Burns SP, Biering-Sorensen F, Donovan W, Graves DE, Jha A, et al. International standards for neurological classification of spinal cord injury (revised 2011). J Spinal Cord Med. 2011;34:535-46.

13. Arnous J, Parnaud E, Denis J. [Safe hemorrhoidectomy. 3,000 operations]. Presse Med. 1971;79:87-90.

14. Bleday R, Pena JP, Rothenberger DA, Goldberg SM, Buls JG. Symptomatic hemorrhoids: current incidence and complications of operative therapy. Dis Colon Rectum. 1992;35:477-81.

15. Bouchard D, Abramowitz L, Castinel A, Suduca JM, Staumont G, Soudan D, et al. One-year outcome of haemorrhoidectomy: a prospective multicentre French study. Colorectal Dis. 2013;15:719-26.

16. Alexander MS, Biering-Sorensen F, Bodner D, Brackett NL, Cardenas D, Charlifue S, et al. International standards to document remaining autonomic function after spinal cord injury. Spinal Cord. 2009; 47:36-43.

17. Krassioukov AV, Karlsson AK, Wecht JM, Wuermser LA, Mathias CJ, Marino RJ. Assessment of autonomic dysfunction following spinal cord injury: rationale for additions to International Standards for Neurological Assessment. J Rehabil Res Dev. 2007;44:103-12.

18. Cosman BC, Vu TT. Lidocaine anal block limits autonomic dysreflexia during anorectal procedures in spinal cord injury: a randomized, double-blind, placebo-controlled trial. Dis Colon Rectum. 2005;48:1556-61.

19. Lestar B, Penninckx F, Kerremans R. The composition of anal basal pressure. An in vivo and in vitro study in man. Int J Colorectal Dis. 1989;4:118-22.

20. Ganio E, Altomare DF, Milito G, Gabrielli F, Canuti S. Long-term outcome of a multicentre randomized clinical trial of stapled haemorrhoidopexy versus Milligan-Morgan haemorrhoidectomy. Br J Surg. 2007;94:1033-7.

21. Higuero T. Update on the management of anal fissure. J Visc Surg. 2015;152:S37-43.

22. Schornagel IL, Witvliet M, Engel AF. Five-year results of fissurectomy for chronic anal fissure: low recurrence rate and minimal effect on continence. Colorectal Dis. 2012;14:997-1000.

23. Krogh K, Christensen P, Sabroe S, Laurberg S. Neurogenic bowel dysfunction score. Spinal Cord. 2006;44:625-31.

24. Emmanuel AV, Chung EA, Kamm MA, Middleton F. Relationship between gut-specific autonomic testing and bowel dysfunction in spinal cord injury patients. Spinal Cord. 2009;47:623-7. 